\title{
DE VERLOREN LOTUSKRUISEN: OOSTERS CHRISTENDOM IN HET CHINEES-MONGOOLSE RIJK
}

In de dertiende eeuw trok een kleine groep volgelingen van de Kerk van het Oosten het steppeland van China en Mongolië in. Daar, in een vestingstad die nu de Stad van de Vele Ruïnes wordt genoemd, bouwden zij een oosters kerkje. Omdat zij tussen verschillende werelden leefden, gebruikten zij voor hun heilige teksten een veelvoud aan oosterse en westerse schriften en versierden zij hun grafstenen met zowel kruisen als Chinese symbolen. De graven van deze vroege christenen zijn inmiddels geplunderd, maar hun grafstenen zijn nog altijd in de steppe van Binnen-Mongolië te vinden (afb. 1). Enkele jaren geleden werd met steun van de Hulsewé-Wazniewski Stichting aan de Universiteit Leiden een project gestart om de grafstenen te documenteren. In het Rijksmuseum voor Volkenkunde in Leiden is een kleine opstelling te zien met foto's en afdrukken van deze bijzondere stenen.

De Nestoriaanse Kerk van het Oosten bereikte China in 635 maar ging al snel ten onder. Zes eeuwen later, onder de Mongoolse overheersing, nam het aantal Christenen in China echter opnieuw toe. Zo was de moeder van Kubilai Khan die in de dertiende eeuw de Yuan dynastie (1271-1368) uitriep, een volgeling van de Kerk van het Oosten. Marco Polo beschreef deze vroege christenen in China en noemde daarbij de legendarische plaats Tenduc. Hoewel Tenduc nooit werd teruggevonden, liggen in het huidige BinnenMongolië de resten van talloze ruïnesteden verborgen. Bij enkele daarvan zijn graven van China's vroege christenen aangetroffen. De grafstenen zijn rijk versierd met motieven en symbolen die vaak van andere religies afkomstig zijn. Zo rijzen de kruisen van de Kerk van het Oosten uit Boeddhistische lotusbloemen op, of worden zij door klassiek Chinese draken omhoog gehouden. Andere kruisen worden onder wolkenpartijen en hemellichamen afgebeeld, zoals oorspronkelijk in het taoïsme gebeurde. Op veel van de stenen zijn Syrische inscripties te zien, maar ook teksten in het Chinees en andere schriften uit Centraal-Azië. Duidelijk is dat de vroege christenen van Binnen-Mongolië goed bekend waren met de talen en religieuze symbolen die in oost en west werden gebruikt. Met de ondergang van het Mongoolse rijk in 1368, werd ook de Kerk van het Oosten uit China verdreven. De kerkjes werden gebrandschat en de vroeg christelijke steden in Binnen-Mongolië verlaten en vergeten.

Binnen-Mongolië werd oorspronkelijk bewoond door nomaden en herders, die in de uitgestrekte steppe hun vee lieten grazen. In de jaren dertig van de vorige eeuw troffen verschillende westerse expedities hier de muren aan van vroeg-christelijke ruïnesteden en grafstenen. $\mathrm{Na}$ de Chinese burgeroorlog en het uitroepen van de Volksrepubliek China in 1949 werd het gebied voor buitenlandse expedities gesloten. Wel trokken miljoenen Chinese migranten naar Binnen-Mongolië, om in de arme steppegrond maïs en anderegewassen $09: 32: 31 \mathrm{AM}$ 


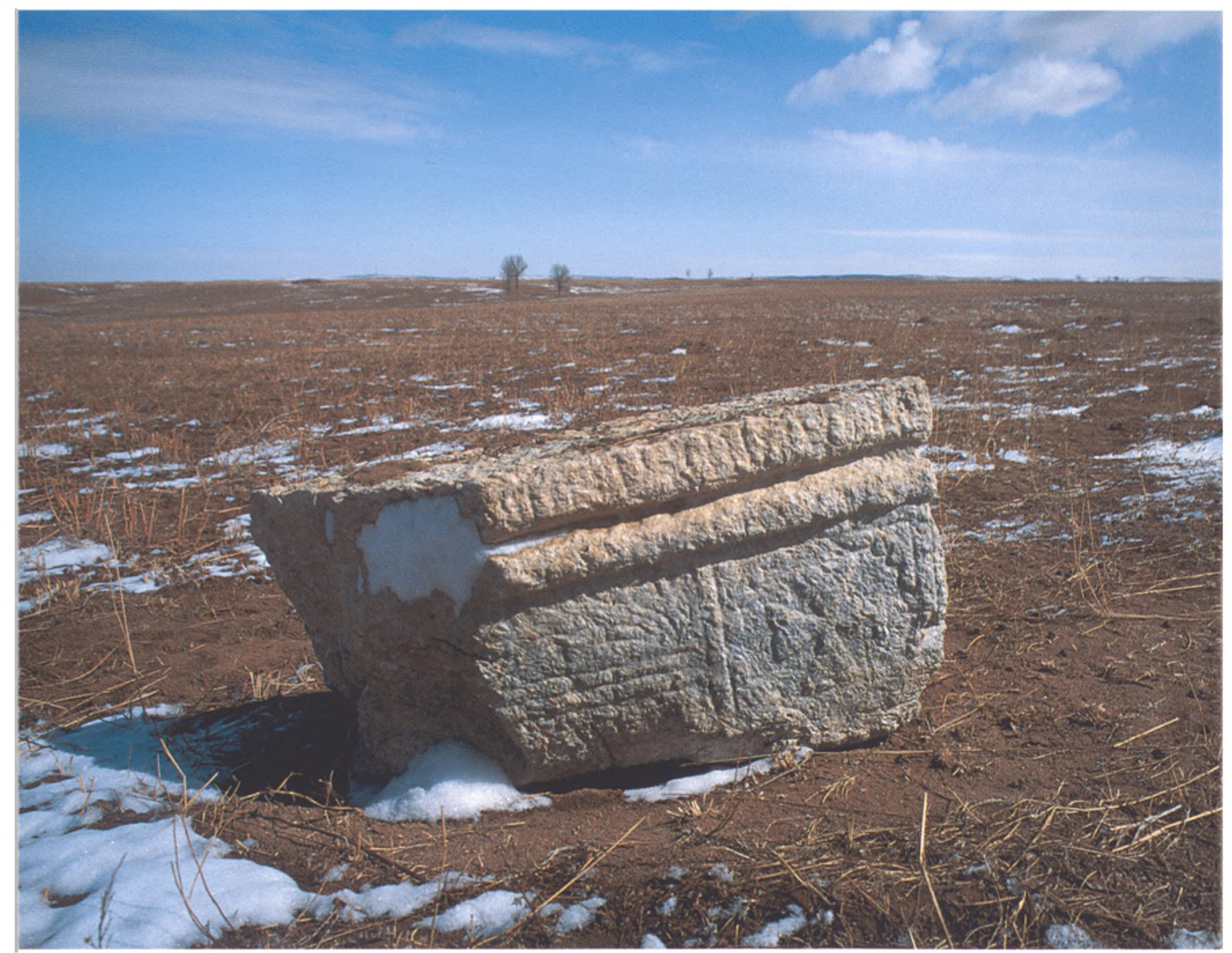

Afbeelding 1 (boven) Crafsteen in de steppe van Binnen-Mongolie, foto auteur

Afbeelding 2 (pagina 35) Grafsteen ingebouwd in de muur van een erf, foto auteur te verbouwen. Inmiddels leven er voor iedere Mongoolse herder bijna tien Han-Chinezen in Binnen-Mongolië. Terwijl de herders in de uitgestrekte steppe wonen, bouwen de Chinese migranten dorpen, die langzaam maar zeker tot steden uitgroeien.

In een landschap waar weinig bomen groeien en bouwmateriaal dus schaars is, wordt ieder stuk steen al snel een kostbaar goed. De grafstenen van de volgelingen van de Chinese Kerk van het Oosten werden dan ook door boeren verzameld, die ze in de muren van hun boerderijen legden of er fundamenten voor huizen van bouwden ( $a f b$. 2). De meeste grafstenen van de vroege christenen in China zijn dan ook niet meer op de grafheuvels te vinden, maar op de erven van boerderijen. Daarnaast lopen deze dertiendeeeuwse graven het gevaar leeggeroofd te worden.

De graven in Binnen-Mongolië worden al eeuwen leeggehaald, maar in de vorige eeuw is de plundering van de oud-christelijke grafheuvels enorm toegenomen ( $\mathrm{afb} .3$ ). In de graftombes zijn muntjes van de Yuan dynastie (1271-1368) te vinden en porseleinen kommen of andere aardewerken grafvoorwerpen. De grafrovers verkopen de voorwerpen aan door het gebied trekkende handelaren. Uiteindelijk komt het antiek vaak in westerse antiekwinkels te liggen, omdat de prijzen daar hoger zijn dan in China zelf o9:32:31Am 


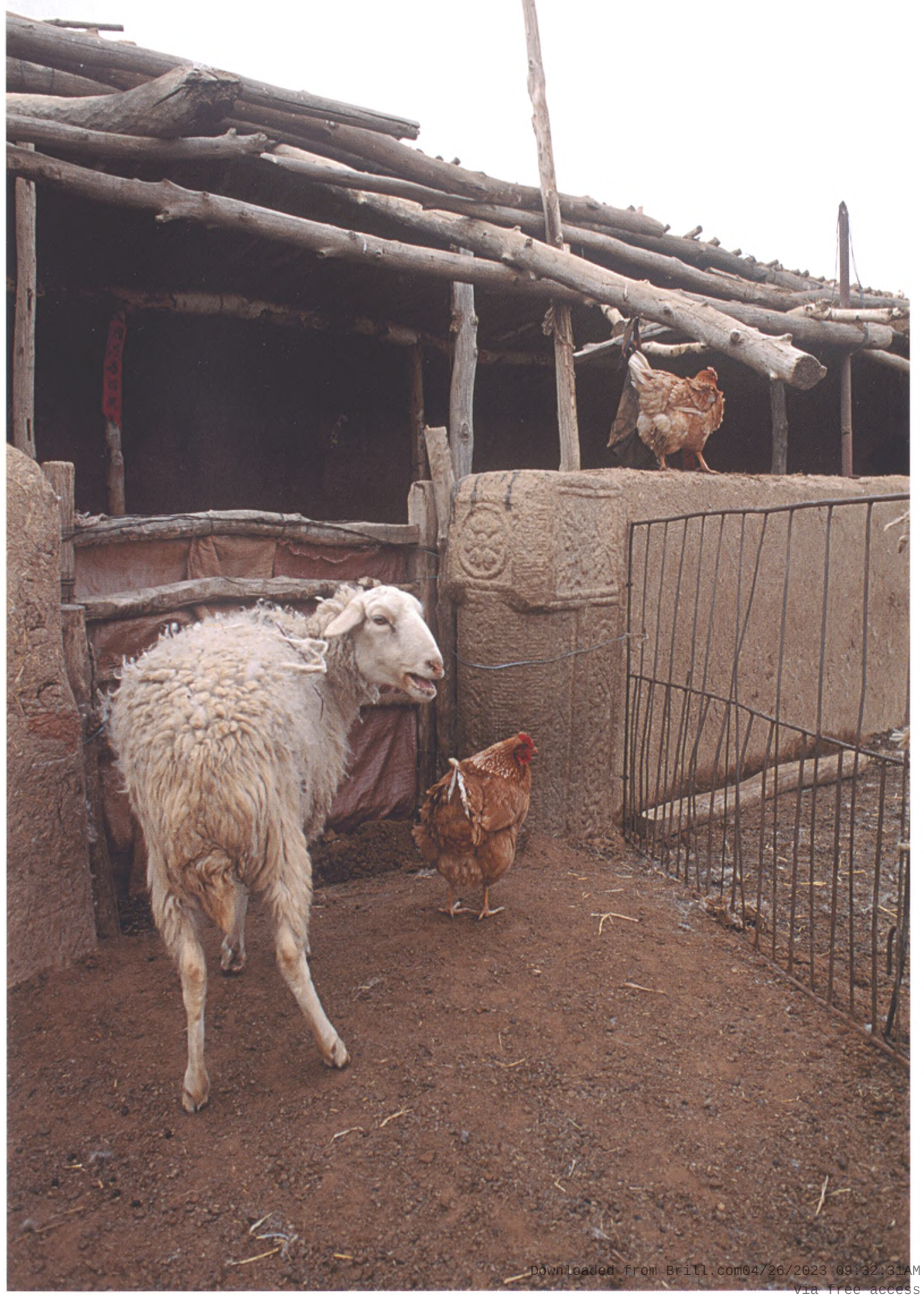




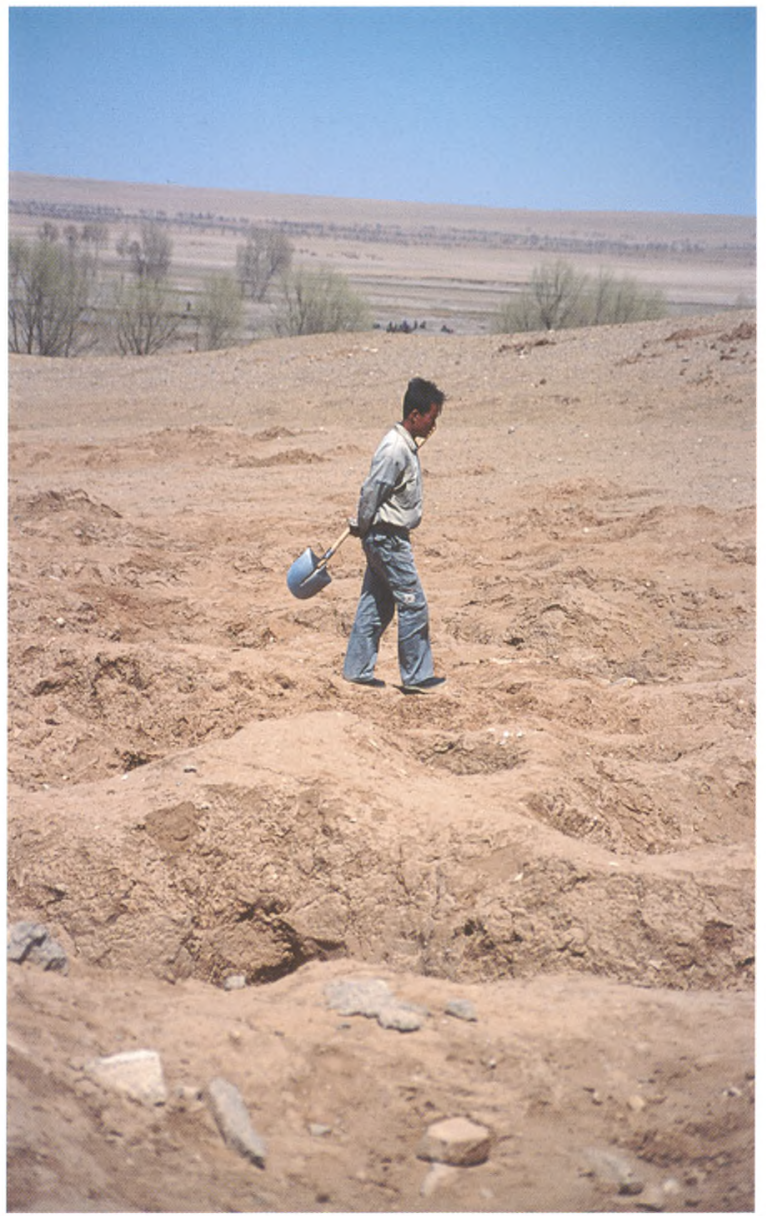

De graven worden echter niet alleen door professionele grafrovers en handelaren geplunderd. Door de droge zomers en strenge winters van de afgelopen tijd hebben veel herders hun vee verloren en hebben de boeren hun oogsten zien mislukken. Om toch over voldoende inkomen te beschikken zijn de boeren en herders naar de grafheuvels getrokken, om de daarin verborgen graven leeg te halen. Veel historische informatie over de Chinese Kerk van het Oosten is daarmee voorgoed verloren gegaan. Het documenteren van dit bijzondere erfgoed door Chinese- en buitenlandse onderzoekers is dan ook belangrijker dan ooit.

Basis voor de tentoonstelling is het onderzoek geweest dat is vastgelegd in het boek: Tjalling Halbertsma, De verloren lotuskruisen - een zoektocht naar de graven steden en kerken van vroege christenen in China, Altamira-Becht, 2002.

Galerij tentoonstelling De Verloren Lotuskruisen Rijksmuseum voor Volkenkunde, Leiden Verlengd tot 26 Juni 2005 


\section{Chinese en Japanse Keramiek en Kunstvoorwerpen}

Veiling: Maandag 2 mei 2005 om 19.00 uur

Kijkdagen:29 april, 1 en 2 mei 2005, dagelijks van 10-17 uur

30 april gesloten

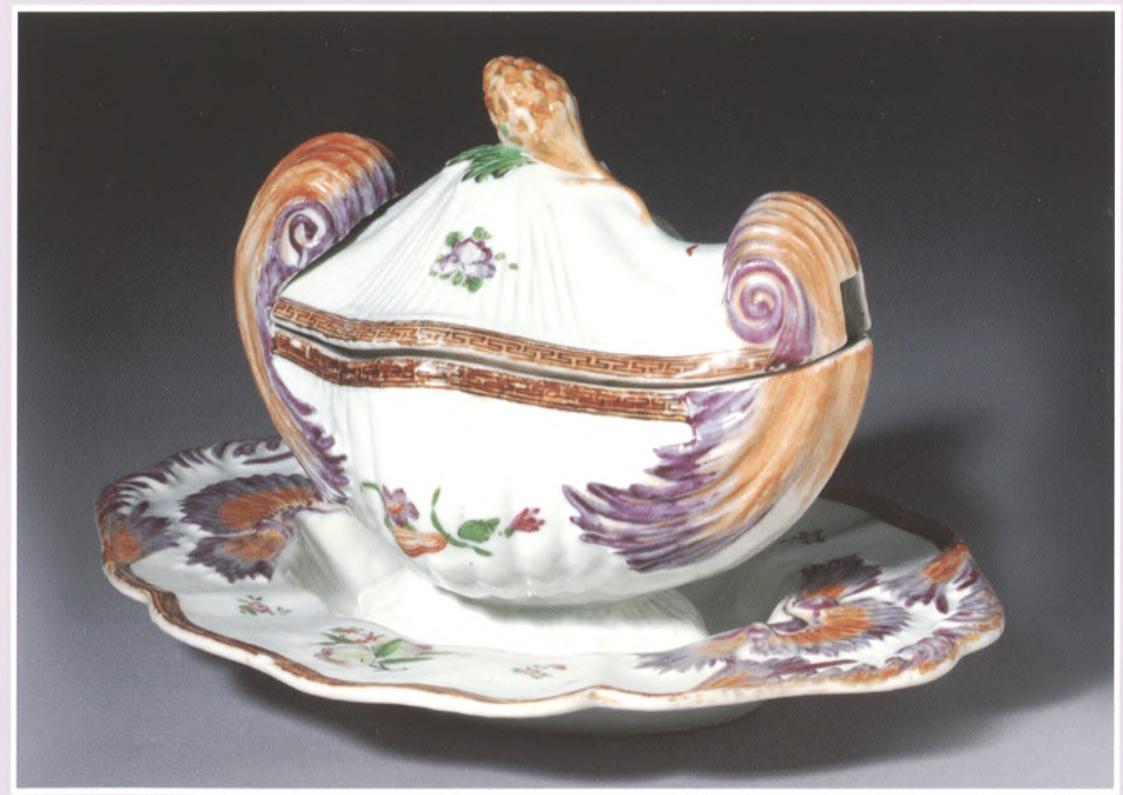

Een zeldzame famille rose Rococo stijl sauskom met deksel en onderschotel, naar een Wedgwood model, Qianlong. Richtprijs € 2.000-3.000

Voor taxaties en inlichtingen over onze najaarsveiling 2005 kunt u contact op nemen met Victor Bouman of Hélène Besançon, tel: 0205502239 victor.bouman@sothebys.com

Sotheby's Amsterdam

De Boelelaan 30

1083 HJ Amsterdam

Tel. 0205502200

www.sothebys.com

\section{Sotheby's}

